ing notation. (For example, the work by Hawthorne and Cohen, on the effect of heating and cooling a compressible flow, appears in three places.) In general the book is of the high calibre expected of the distinguished authors and editor, and all physicists, mathematicians and engineers working in the field will be grateful for the publication of this volume.

J. H. HORLOCK

\section{MICROSCOPES AND PHOTOMICROGRAPHY}

The Practical Use of the Microscope

Including Photomicrography. By George Herbert Needham. Pp. xxiv + 493. (Springfield, Ill. : Charles C. Thomas; Oxford: Blackwell Scientific Publications, 1958.) 117s. 6d.

Photomicrography

By Dr. Roy M. Allen. Second edition. Pp. xiii +441 (54 plates). (Princeton, N.J. : D. Van Nostrand Company, Inc.; London : D. Van Nostrand Company, Ltd., 1958.) 67s. 6d.

Applied Microscopy and Photomicrography

By H. M. Malies. Pp. $143+12$ plates. (London: Fountain Press, 1959.) 22s. 6d. net.

N many branches of scientific work the need to 1 take photomicrographs arises both for record purposes and to illustrate lectures and published works. It is generally accepted that success in photomicrography primarily depends upon a thorough knowledge of microscopical principles and the correct use of the microscope ; it is with this that the book by G. H. Needham is more concerned. From a study of the list of contents, it would seem that in scope and breadth of treatment this would be a most valuable book; unfortunately this does not prove to be the case, for here is one book which definitely cannot be recommended. The treatment is unjustifiably dogmatic, and much of the matter is obsolete, for example, the chapter on electron microscopy, which only makes a passing reference to the technique of thin-sectioning. Other valuable modern techniques such as phase-contrast and interference microscopy receive only a sketchy treatment.

Although the book is profusely illustrated, it is felt that many of the photographs, particularly those of microscopes, are superfluous. The essential features in a chapter on binocular microscopes, for example, are certainly not photographs of the stands, but diagrams which give the reader valuable information on, say, the arrangement of the prism trains and path of the light rays. It is these features which are conspicuous by their absence. The book has not even the merit of correct English or clear explanation to cornmend it. The glossary of microscopical terms included in the book may be taken as representative of the general standard: thus it is stated that "there is no connection between the focal length of an objective and its working distance, except that they are directly proportional' ! It seems that there is still need for a comprehensive reference work on microscopy.

The other two books may be recommended without reserve. Dr. Allen's well-known "Photomicrography" appears in a revised and enlarged edition which gives a straightforward account of the principles and practice of photomicrography, including a chapter on home-made equipment which should prove useful to the enthusiast who has not the resources of a fully equipped laboratory at his disposal. There is also an adequate section on the purely photographic aspects which should prove valuable to many. The book by H. M. Malies has the great advantage of a low price, but it may be said at once that one gets very good value for money as it gives a clear account of basic microscopical technique. There are many good line illustrations and plates. A minor shortcoming is the lack of detailed information on the photographic processes involved in the making of a photomicrograph; I would have liked to see a section on the use of the $35-\mathrm{mm}$. camera included, in view of the increasing popularity of this size of negative for much of the routine photomicrography carried out to-day.

S. BRADBURY

\section{LOW-TEMPERATURE ENGINEERING}

\section{Cryogenic Engineering}

By Russell B. Scott. Pp. xi +368 . (Princeton, N.J. : D. Van Nostrand Company, Inc.; London: D. Van Nostrand Company, Ltd., 1959.) 5.60 dollars ; $42 \mathrm{~s}$.

7 'HE word 'cryogenic' has come into fashion during the past five years and is intended to embrace all practical applications of low temperatures (say below - $150^{\circ} \mathrm{C}$.). In fact, it connotes, at the present time, a more restricted field in which the main emphasis is on techniques for the liquefaction and handling of low-temperature rocket fuels and oxidants, and special apparatus for low-temperature research. The main fields of industrial low-temperature application, namely, air separation and ethylene production, remain largely outside its orbit. This emphasis is clear in Dr. Scott's book and arises naturally from the fact that the work of the U.S. Bureau of Standards Cryogenic Laboratory at Boulder, Colorado, of which he is head, has concentrated on the new applications of very low temperatures.

The book is exceptionally valuable because the author combines a masterly understanding of the theory of his subject with access to detailed information on the most modern techniques, which he freely imparts.

The chapter on gas liquefaction is useful because of its comprehensiveness and its detailed treatment of heat-exchanger design. Hydrogen and helium liquefaction feature largely. Gas separation is intentionally given only token reference, but this is compensated for by a useful treatment of gas purification by adsorption.

Low-temperature thermometry is covered comprehensively and lucidly, as one might expect from an exponent of the subject.

The storage and piping of liquefied gases is discussed in great detail, both theoretically and practically. It is probable that the material given will be adopted as the standard text for many years to come.

The final chapters of the book contain a compilation of the properties of cryogenic fluids and structural materials at low temperatures, gathered and sifted with the full resources of the National Bureau of Standards.

The book is well written, and contains an ample bibliography.
G. G. HASELDEN 